\title{
Lymphovascular invasion and extranodal tumour extension are risk indicators of breast cancer related lymphoedema: an observational retrospective study with long-term follow-up
}

Marco Invernizzi ${ }^{1+}$, Chiara Corti ${ }^{2,3+}$, Gianluca Lopez ${ }^{2}$, Anna Michelotti ${ }^{2,3,5}$, Luca Despini ${ }^{4}$, Donatella Gambini ${ }^{5}$, Daniele Lorenzini ${ }^{2,6}$, Elena Guerini-Rocco ${ }^{7,8}$, Stefania Maggi ${ }^{9}$, Marianna Noale ${ }^{9}$ and Nicola Fusco ${ }^{2,10^{*}}$ (D)

\begin{abstract}
Background: Breast cancer related lymphoedema (BCRL) occurs in a substantial proportion of breast cancer survivors and is a major contributor to patients' disability. Regrettably, there are no validated predictive biomarkers, diagnostic tools, and strong evidence-supported therapeutic strategies for BCRL. Here, we provide an integrative characterization of a large series of women with node-positive breast cancers and identify new bona fide predictors of BCRL occurrence.

Methods: Three hundred thirty-two cases of surgically-treated node-positive breast cancers were retrospectively collected (2-10.2 years of follow-up). Among them, 62 patients developed BCRL. To identify demographic and clinicopathologic features related to BCRL, Fisher's exact test or Chi-squared test were carried out for categorical variables; the Wilcoxon rank-sum was employed for continuous variables. Factors associated with BCRL occurrence were assessed using a Cox proportional hazards regression model.

Results: En-bloc dissection of the axillary lymph nodes but not the type of breast surgery impacted on BCRL development. Most of BCRL patients had a Luminal A-like neoplasm. The median number of lymph nodes involved by metastatic deposits was significantly higher in BCRL compared to the control group $(p=0.04)$. Both peritumoral lymphovascular invasion (LVI) and extranodal extension (ENE) of the metastasis had a negative impact on BCRL-free survival $(p=0.01)$. Specifically, patients with LVI and left side localization harboured 4 -fold higher risk of developing $B C R L$, while right axillary nodes metastases with ENE increased the probability of BCRL compared to ENE-negative patients.
\end{abstract}

Conclusions: Assessment of LVI and ENE should be integrated with clinical and surgical data to improve BCRL risk stratification.

Keywords: Breast cancer related lymphoedema, Breast cancer, Lymphovascular invasion, Extracapsular extension, Axillary lymph nodes dissection

\footnotetext{
* Correspondence: nicola.fusco@unimi.it

${ }^{+}$Marco Invernizzi and Chiara Corti contributed equally to this work.

2Division of Pathology, Fondazione IRCCS Ca' Granda, Ospedale Maggiore

Policlinico, Via Francesco Sforza 35, 20122 Milan, Italy

${ }^{10}$ Department of Biomedical, Surgical and Dental Sciences, University of

Milan, Via Commenda 10, 20122 Milan, Italy

Full list of author information is available at the end of the article
}

(c) The Author(s). 2018 Open Access This article is distributed under the terms of the Creative Commons Attribution 4.0 International License (http://creativecommons.org/licenses/by/4.0/), which permits unrestricted use, distribution, and

reproduction in any medium, provided you give appropriate credit to the original author(s) and the source, provide a link to the Creative Commons license, and indicate if changes were made. The Creative Commons Public Domain Dedication waiver (http://creativecommons.org/publicdomain/zero/1.0/) applies to the data made available in this article, unless otherwise stated. 


\section{Background}

Breast cancer related lymphoedema (BCRL) is a secondary lymphoedema of the upper limb that occurs in up to $54 \%$ of breast cancer patients after surgery and/or regional nodal irradiation $[1,2]$. Its pathogenesis is currently considered the result of a blockage of the lymphatic fluid from the arm and/or breast, leading to lymph retention [3]. Despite BCRL median onset is 14-18 months post-surgery [4-6], this condition represents a lifelong threat to breast cancer survivors and shows high recurrence rates [7]. Due to the impairment of the upper extremities function and increased comorbidities (e.g. skin infections), BCRL often leads to psychophysical frailty and has a detrimental impact on women's social life, work, and career [5, 8-11]. Regrettably, the few guidelines available for the diagnosis, screening, and risk assessment of BCRL are not widely adopted [12]. As a result, BCRL patients are often managed using vastly heterogeneous Institution-dependent schemes, in contrast with breast cancer standard of care $[13,14]$.

The impact that BCRL has both on women's health and on sanitary costs has led to several lines of research and novel clinical approaches for the prevention and treatment of this condition [5, 1518]. During the past few years, new strategies have been proposed, such as axillary reverse mapping [19], microsurgical techniques (e.g. LYMPHA) [20], and decongestive physical therapies [21]. These methods together with physical exercise, skin care, and risk factors overall reduction, are grouped in the complex decongestive treatment strategy, a multidisciplinary approach for BCRL clinical management [22]. Despite the great efforts that have been made, the high prevalence of BCRL and the low number of individuals who experience complete remission have currently plateaued [5]. This could be due, at least in part, to the lack of detailed knowledge on the biology underpinning this condition.

Given the extremely high incidence of breast cancer worldwide [23], and the increasing number of long-term survivors [13], the reduction of BCRL burden represents an urgent clinical need in women's healthcare. However, our ability to identify high-risk individuals remains extremely limited in BCRL, given the lack of reliable biomarkers and predictive tools. Furthermore, net of the mechanistic explanations of its pathogenesis, there are no available data in the literature on tumour-specific features related to BCRL. In this scenario, the aim of the current study was to provide a comprehensive clinicopathological characterization of a large series of surgically-treated node-positive breast cancers with long-term follow-up and to identify clinically relevant subclasses of patients at risk of developing BCRL.

\section{Methods}

\section{Case selection}

This study was fully compliant with the local ethical guidelines and granted Institutional Review Board approval. The medical records of the Fondazione IRCCS $\mathrm{Ca}^{\prime}$ Granda Ospedale Maggiore Policlinico, Milan, Italy were searched for breast cancers patients who underwent surgical procedures involving both the breast and axilla, including lumpectomy, quadrantectomy, and mastectomy (simple, nipple-sparing, skin-sparing, or radical) with sentinel and/ or axillary node(s) excision. Three additional cases were collected from the Division of Physical and Rehabilitative Medicine, University of Eastern Piedmont "A. Avogadro", Italy. Only patients with data on the presence or absence of upper limb lymphoedema, for which all histologic slides were available for review, as well as detailed clinical and > 2 years follow-up data, were included. Patients with very small incisional biopsies (e.g. core needle biopsy) of the tumour and sentinel lymph node, prior breast surgery (including implants), with tumour measuring $<1 \mathrm{~mm}$ in greatest dimensions (i.e. pTmi), with a family history of breast or ovarian cancer and/or BRCA1 or BRCA2 mutation, current pregnancy or lactation, or who received neoadjuvant therapy were excluded. Patients were anonymized prior to data collection and analysis. Clinical data included body mass index (BMI), menopausal status, metabolic conditions (e.g. diabetes, dyslipidaemia), infections of the urinary tract, gastroenteric system, and respiratory, type of breast and axillary surgery, therapeutic protocols, and BCRL, which was assessed using a semi-quantitative system during the follow-up oncology visits [24, 25]. Specifically, for all patients with macroscopic evidence of BCRL, the arm volume was measured at different levels from the wrist to humeral head using a circumferential tape and compared to the contralateral arm, as previously described [26].

\section{Histopathologic review}

All cases were re-classified and graded following the latest World Health Organization criteria [27] and the Nottingham grading system [28], respectively. Pathological re-staging was performed according to the 8th edition of the AJCC Cancer Staging Manual [29]. As previously described [30], breast cancer intrinsic molecular subtypes were determined by oestrogen receptor (ER), progesterone receptor (PR), Ki67, and Human epidermal growth factor receptor 2 (HER2) status following the 2017 St Gallen International Expert Consensus recommendations [31]. All diagnostic slides comprising the tumours and lymph nodes were retrieved from the archive and reviewed by two independent breast pathologists (EGR and NF). Discordant results were resolved during a dedicated consensus session. Lymphovascular invasion (LVI) was assessed in the peritumoral tissue on haematoxylin and eosin stained sections according to the criteria proposed by Rosen [32] and 
endorsed by the College of American Pathologists in the 2017 Protocol for the examination of specimens from patients with invasive carcinoma of the breast (v.4.0.0.0, available at www.cap.org/cancerprotocols). Briefly, LVI was defined by the presence of cancer cells within a definite, endothelial-lined space outside the border of the invasive carcinoma, regardless of the vessel type (i.e. blood or lymphatics) [33]. Tumour emboli with the same shape of the vessel-like structure were considered retraction artefacts [32]. Extranodal extension (ENE) of the metastasis, also referred to as extracapsular extension, was defined by the presence of full-thickness lymph node capsular invasion or extension of tumor cells beyond the lymph node capsule [34-37]. No dimensional cut-off values were employed to assess the extranodal extension.

\section{Statistical analysis}

Categorical variables were represented as the number of patients and the corresponding percentage, whereas continuous variables were summarized through the mean and standard deviation (SD) or through the median and the quartiles (Q1, Q3). Normal distributions of continuous variables were tested using the Shapiro-Wilk test. Relationships between the presence of BCRL and the characteristics of the patient population (i.e. demographic and clinical traits, data on treatment, and pathological features) were assessed using Fisher's exact test or Chi-squared test for categorical variables, while the Wilcoxon rank-sum test was employed for the continuous variables. Cox's proportional hazard regression analysis was used to identify factors associated with BCRL occurrence. A purposeful selection of covariates was applied as described elsewhere [38]. The proportional hazard assumption was verified considering Schoenfeld's residuals of the covariates. In the Cox multivariable model employed, the rule of 10 events per factors was relaxed, as previously described [39]. This allowed for the development of an acceptable model encompassing 5-9 events per predictor. The linearity assumption was evaluated for quantitative variables considering an analysis of quartiles [40]. The presence of significant interactions was also assessed. The hazard ratio (HR) and corresponding 95\% confidence intervals $(\mathrm{CI})$ were calculated for each predictor. Survival curves were built according to the Kaplan-Meier method and compared using Log-Rank tests [41]. All statistical tests were two-tailed and $p$-values $<0.05$ were considered statistically significant. All the analyses were performed using the SAS 9.4 statistical software (SAS Institute, Cary, NC, USA).

\section{Results}

A total 332 patients (age, 26-88 years; median, 60 years) with node-positive $(N \geq 1)$ breast cancers who were subjected to breast surgery between 1998 and 2015 (follow-up time 2-10.2 years) were included in this study. Their demographic and general characteristics are listed in Table 1 and Additional file 1: Table S1. Among them, $62(18.7 \%)$ patients developed BCRL after 0.4-8.6 years, whereas the remaining $270(81.3 \%)$ patients never showed signs of BCRL.

\section{Type of axillary surgery but not breast surgery impacts on BCRL occurrence}

Simple, nipple-sparing, skin-sparing, or radical mastectomy was performed in 22 (36\%) BCRL and 106 (39\%) no-BCRL patients, while $40(65 \%)$ and 164 (61\%) women, respectively, underwent quadrantectomy (Table 1). None of the patients included in this study experienced BCRL without a prior full axillary dissection $(p=0.05)$. Most of BCRL patients $(n=48,77 \%)$ were subjected to prior radiotherapy, which included irradiation of the residual breast $(n=33$, $53 \%)$, residual breast and supraclavicular fossa $(n=7,11 \%)$, and supraclavicular fossa and chest wall $(n=8,13 \%)$. No statistically significant correlations between radiotherapy and BCRL occurrence were observed $(p=0.4)$. During that time period, no patients received axillary surgery and axillary radiation. These observations corroborate the notion that the en bloc resection of axillary tissue increases the risk of BCRL more than the only sentinel lymph node excision, irrespective of the type of breast surgery.

\section{Clinicopathological features of breast cancers that developed BCRL}

Among BCRL patients $(n=62)$, we observed a significantly high prevalence $(n=41,66 \%)$ of late post-surgery BCRL in node-positive breast cancers of the left breast, in contrast to no-BCRL patients $(p=0.01)$, as depicted in Fig. 1 and Table 2. Although the most frequently diagnosed tumour type was the invasive carcinoma of no special type (also known as ductal carcinoma) regardless of the BCRL status, the prevalence of other histological types was lower but not significant in BCRL patients (11\% vs. $19 \%)$. Most tumours $(n=39,63 \%)$ measured less than $2 \mathrm{~cm}$ in greatest dimension, being staged as pT1, and were moderately to poorly differentiated (Fig. 1), according to the Nottingham score system [42]. Not surprisingly, most cases were ER positive, PR positive, and HER2-negative (Fig. 1, Table 2). Consistently with the long survival rates that favour BCRL onset, the most frequent molecular subtype $(n=30,48 \%)$ was the Luminal A-like (Fig. 1 , Table 2 ). Despite no radiations were administered in the axilla, the median number of lymph nodes involved by metastatic deposits was significantly higher $(p<0.05)$ in BCRL patients $(n=3$, range $1-7)$ compared to no-BCRL $(n=2$, range 1-5), as shown in Table 2. Peritumoral LVI (Fig. 2) was observed in $47 \%$ of BCRL, with significantly higher rates $(p<0.01)$ compared to the no-BCRL group (Table 2 ). Overall, ENE of the lymph node metastasis was identified in 212/332 (63\%) tumors (Fig. 3). Among them, the prevalence of ENE-positive cases was higher in the BCRL group 
Table 1 Demographic data and treatment information of the patients included in this study, according to their breast cancer related lymphoedema status

\begin{tabular}{|c|c|c|c|c|c|c|c|}
\hline \multirow[t]{2}{*}{ Side } & \multicolumn{3}{|l|}{$B C R L$} & \multicolumn{3}{|l|}{ No BCRL } & \multirow{2}{*}{$\begin{array}{l}p- \\
\text { value }\end{array}$} \\
\hline & $\begin{array}{l}\text { Left } \\
(n=21)\end{array}$ & $\begin{array}{l}\text { Right } \\
(n=41)\end{array}$ & $\begin{array}{l}\text { Total } \\
(n=62)\end{array}$ & $\begin{array}{l}\text { Left } \\
(n=140)\end{array}$ & $\begin{array}{l}\text { Right } \\
(n=130)\end{array}$ & $\begin{array}{l}\text { Total } \\
(n=270)\end{array}$ & \\
\hline Age at diagnosis, years, mean \pm SD & $60.4 \pm 12.5$ & $56.6 \pm 13.0$ & $57.9 \pm 12.8$ & $58.7 \pm 13.0$ & $60.4 \pm 13.0$ & $59.5 \pm 13.0$ & 0.4734 \\
\hline $\mathrm{BMI}, \mathrm{n}(\%)^{\mathrm{a}}$ & & & & & & & 0.5432 \\
\hline Underweight & 0 & $1(2.4)$ & $1(1.6)$ & $4(2.9)$ & $1(0.8)$ & $5(1.9)$ & \\
\hline Normal weight & $14(66.7)$ & $13(31.7)$ & $27(43.6)$ & $66(47.1)$ & $55(42.3)$ & $121(44.8)$ & \\
\hline Overweight & $3(14.3)$ & $18(43.9)$ & $21(33.9)$ & $26(18.6)$ & $44(33.8)$ & $70(25.9)$ & \\
\hline Obesity & $4(19.0)$ & $9(22.0)$ & $13(21.0)$ & $44(31.4)$ & $30(23.1)$ & $74(27.4)$ & \\
\hline Menopause, n (\%) & & & & & & & 0.2647 \\
\hline Pre-menopausal & $5(23.8)$ & $16(39.0)$ & $21(33.9)$ & $45(32.1)$ & $34(26.2)$ & $79(29.3)$ & \\
\hline Peri-menopausal & 0 & 0 & $0(0.0)$ & $5(3.6)$ & $5(3.8)$ & $10(3.7)$ & \\
\hline Post-menopausal & $16(76.2)$ & $25(61.0)$ & $41(66.1)$ & $90(64.3)$ & $91(70.0)$ & $181(67.0)$ & \\
\hline Axillary surgery, n (\%) & & & & & & & 0.0503 \\
\hline Radical lymph node dissection & $21(100)$ & $41(100)$ & $62(100)$ & $130(92.8)$ & $123(94.6)$ & $253(93.7)$ & \\
\hline Sentinel lymph node dissection & 0 & 0 & 0 & $10(7.2)$ & $7(5.4)$ & $17(6.3)$ & \\
\hline Radiotherapy, n (\%) & & & & & & & 0.3536 \\
\hline Breast & $11(52.4)$ & $22(53.6)$ & $33(53.2)$ & $76(54.3)$ & $72(55.4)$ & $148(54.8)$ & \\
\hline Breast and supraclavicular fossa & $1(4.8)$ & $6(14.6)$ & $7(11.3)$ & $7(5.0)$ & $7(5.4)$ & $14(5.2)$ & \\
\hline Supraclavicular fossa and chest wall & $4(19.0)$ & $4(9.8)$ & $8(12.9)$ & $22(15.7)$ & $17(13.1)$ & $39(14.4)$ & \\
\hline No & $5(23.8)$ & $9(22.0)$ & $14(22.6)$ & $35(25.0)$ & $34(26.1)$ & $69(25.6)$ & \\
\hline Chemotherapy, n (\%) & & & & & & & 0.0025 \\
\hline Taxane-based protocol & $11(52.4)$ & $27(65.9)$ & $38(61.3)$ & $61(43.6)$ & $40(30.8)$ & $101(37.4)$ & \\
\hline Other protocols & $1(4.8)$ & $4(9.7)$ & $5(8.1)$ & $14(10.0)$ & $14(10.8)$ & $28(10.4)$ & \\
\hline No & $9(42.9)$ & $10(24.4)$ & $19(30.7)$ & $65(46.4)$ & $76(58.4)$ & $141(52.2)$ & \\
\hline Hormone therapy, n (\%) & & & & & & & 0.0959 \\
\hline Yes & $16(76.2)$ & $34(82.9)$ & $50(80.7)$ & $128(91.4)$ & $111(85.4)$ & $239(88.5)$ & \\
\hline No & $5(23.8)$ & $7(17.1)$ & $12(19.3)$ & $12(8.6)$ & 19 (14.6) & $31(11.5)$ & \\
\hline Trastuzumab, n (\%) & & & & & & & 0.0140 \\
\hline Yes & $2(9.5)$ & $7(17.1)$ & $9(14.5)$ & $7(5.0)$ & $8(6.2)$ & $15(5.6)$ & \\
\hline No & $19(90.5)$ & $34(82.9)$ & $53(85.5)$ & $133(95.0)$ & $122(93.8)$ & $255(94.4)$ & \\
\hline
\end{tabular}

Abbreviations: $B C R L$ Breast cancer related lymphoedema, $B M I$ Body Mass Index

${ }^{\mathrm{a}} \mathrm{BMI}$ was stratified using the WHO International Classification of adult underweight, overweight and obesity, as follows: underweight, $<18.5 \mathrm{~kg} / \mathrm{m}^{2}$; normal weight, $18.5-24.99 \mathrm{~kg} / \mathrm{m}^{2}$; overweight, $25-29.99 \mathrm{~kg} / \mathrm{m}^{2}$; obesity, $\geq 30 \mathrm{~kg} / \mathrm{m}^{2}$

${ }^{\mathrm{b}}$ Menopausal status was defined according to WHO guidelines. Specifically, menopause is recognized to have occurred after 12 consecutive months of amenorrhea, for which there is no other obvious pathological or physiological cause; peri-menopause is defined as the period immediate prior to the menopause - when the endocrinological, biological, and clinical features of approaching menopause commence, for example variability in the menstrual cycle is increased and the first 12 months after menopause; pre-menopausal status is used to describe the whole of the reproductive period prior to the menopause

(74\% vs. $62 \%, p=0.06)$. These data suggest that tumour-specific pathologic features are likely to represent risk indicators of BCRL.

Lymphovascular invasion and extranodal extension increase the risk of BCRL according to the side of surgery Log-rank test showed that tumour laterality $(p<0.01)$, peritumoral LVI $(p<0.01)$, and ENE $(p=0.04)$ of the lymph node metastases had a significant impact on BCRL-free survival, as represented in Fig. 4. Analysis of the HR using the
Cox regression showed that the presence of LVI represented a significant risk factor within left-side BCRL (HR = $3.78,95 \%$ CI (1.57-9.10)), in contrast to the patients with LVI and right side involved $(\mathrm{HR}=1.43$, 95\% CI $(0.75-$ 2.73)), as shown in Table 3 and Fig. 5 a. On the other hand, patients who underwent axillary surgery for a node-positive breast cancer located in the right side had more than 3-fold higher risk to suffer BCRL if the macrometastases displayed ENE (HR $=3.38$, 95\% CI (1.53-7.49)), as shown in Table 3. Interestingly, a similar observation could not be made for 


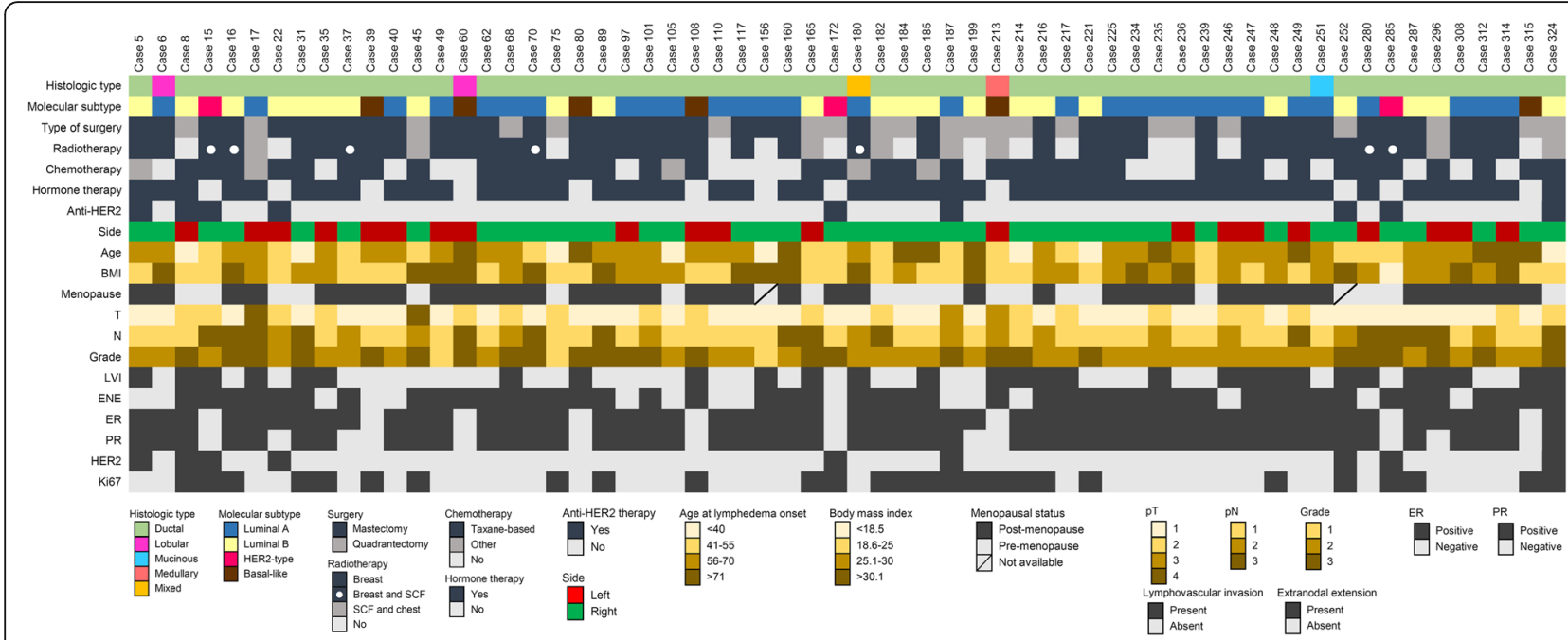

Fig. 1 Overview of 62 node-positive breast carcinomas with associated ipsilateral lymphoedema after surgery. Heatmap illustrating the histologic and biological features, surgical, and clinical information. Each column represents a case, each row a parameter, which is color-coded according to the key below. BMI, body mass index; LVI, lymphovascular invasion; ENE, extranodal extension; ER, estrogen receptor; PR, progesterone receptor; SCF, supraclavicular fossa

the patients with ENE and left-side BCRL ( $\mathrm{HR}=0.73$, 95\% CI (0.30-1.78)). In particular, BCRL-free survival was significantly better in right-side breast cancers showing no ENE compared to ENE-positive cases (Fig. 5b). Taken together, the interaction between the side of dissection and ENE resulted statistically significant $(p=0.01)$. On the other hand, there was no difference in BMI, N-stage, and presence of ENE and LVI between patients who were left- or right-handed, as detailed in Additional file 1: Table S1. Consistent with these findings, the interaction between LVI and ENE appeared borderline significant $(p=0.07)$. These data provide evidence consistent with the notion that the routinary assessment of LVI and ENE, that is currently made for prognostic purposes, might be integrated with clinical and surgical data to predict which node-positive breast cancer patients are at higher risk to develop BCRL. Other patients' clinical conditions significantly associated with the development of BCRL included dyslipidaemia ( $p=$ $0.04)$ and post-surgery infections $(p=0.05)$, confirming the prominent role of the clinical milieu in BCRL occurrence. The distribution of right- and left-sided breast cancers according to the presence of ENE and LVI is shown in Additional file 1: Table S2.

\section{Discussion}

BCRL is a relatively frequent condition that, despite being not lethal per se, is extremely detrimental to the quality of life of breast cancer survivors. All breast cancer patients who undergo breast surgery and/or irradiation of the axilla are at risk for lymphoedema, while cases showing complete remission remain rare to date [43]. BCRL shows poor response to surgical, physical, and medical therapies, so guidelines for the management of these women need to be further implemented. Here, we performed a comprehensive clinicopathologic analysis of a large series of surgically-treated node-positive breast cancers with long-term follow-up and found that LVI and ENE have a strong predictive value for BCRL occurrence. Furthermore, to achieve the optimal risk stratification, we documented that the analysis of these two prognostic variables should be integrated with information on the laterality of the tumour and the surgical procedure. Finally, we confirm that the full excision of the axillary nodes is one of the major determinants of $\mathrm{BCRL}$, regardless of the extent of the surgical procedure involving the breast.

The scarcity of literature on BCRL risk indicators is reflected by the absence of clinical nomogram to select patients who would benefit more from tailored anti-lymphoedema surgical and medical interventions. In our study, we observed that women with metastatic breast cancer of the left breast that undergo en bloc axillary resection are more likely to develop BCRL compared to patients with right-sided breast cancer. To our knowledge, this is the first time that data on surgery laterality are implicated in BCRL pathogenesis. One of the possible explanations of this observation involves the protective role of physical exercise. Indeed, in contrast to the historical concept that patients after radical lymphadenectomies should avoid physical activity, recent guidelines recommend supervised exercise of the arm to reduce the risk of lymphoedema development [44]. Despite complete data on the dominant arm of our patients were not available, we can posit that the patients included in this study displayed the same prevalence of 
Table 2 Association between breast cancer related lymphoedema and other clinicopathologic variables

\begin{tabular}{|c|c|c|c|}
\hline & $\begin{array}{l}\text { BCRL } \\
(n=62)\end{array}$ & $\begin{array}{l}\text { No BCRL } \\
(n=270)\end{array}$ & $p$-value \\
\hline Side, left n (\%) & $41(66.1)$ & $130(48.2)$ & 0.0106 \\
\hline Histological type, n (\%) & & & 0.1734 \\
\hline NST & $55(88.7)$ & $220(81.5)$ & \\
\hline Others & $7(11.3)$ & $50(18.5)$ & \\
\hline T-staging, n (\%) ${ }^{\mathrm{a}}$ & & & 0.5922 \\
\hline $\mathrm{T} 1$ & $39(62.9)$ & $157(58.2)$ & \\
\hline $\mathrm{T} 2$ & $19(30.7)$ & $80(29.6)$ & \\
\hline $\mathrm{T} 3$ & $2(3.2)$ & $10(3.7)$ & \\
\hline $\mathrm{T} 4$ & $2(3.2)$ & $23(8.5)$ & \\
\hline $\mathrm{N}, \mathrm{n}(\%)^{\mathrm{b}}$ & & & 0.1052 \\
\hline N1 & $33(53.2)$ & $176(65.2)$ & \\
\hline N2 & $13(21.0)$ & $53(19.6)$ & \\
\hline N3 & $16(25.8)$ & $41(15.2)$ & \\
\hline$G, n(\%)^{c}$ & & & 0.6725 \\
\hline 1 & $3(4.8)$ & $22(8.2)$ & \\
\hline 2 & $33(53.2)$ & $139(51.5)$ & \\
\hline 3 & $26(41.9)$ & $109(40.4)$ & \\
\hline ER positive, $\mathrm{n}(\%)$ & $53(85.5)$ & $241(89.3)$ & 0.3998 \\
\hline PR positive, n (\%) & $49(79.0)$ & $226(83.7)$ & 0.3791 \\
\hline HER2 positive, $n(\%)^{d}$ & $9(14.5)$ & $22(8.2)$ & 0.1202 \\
\hline Ki67 positive, $\mathrm{n}(\%)^{\mathrm{e}}$ & $28(45.2)$ & $102(37.8)$ & 0.2828 \\
\hline Molecular subtype, n (\%) & & & 0.6807 \\
\hline Luminal A & $30(48.4)$ & $147(54.4)$ & \\
\hline Luminal B (HER2+) & $5(8.1)$ & $12(4.4)$ & \\
\hline Luminal B (HER2-) & $18(29.0)$ & $82(30.4)$ & \\
\hline HER2-type & $3(4.8)$ & $10(3.7)$ & \\
\hline Basal & $6(9.7)$ & $19(7.0)$ & \\
\hline ENE, n (\%) & $46(74.2)$ & $166(61.5)$ & 0.0603 \\
\hline N. metastatic lymph., median (Q1, Q3) & $3(1,7)$ & $2(1,5)$ & 0.0470 \\
\hline Total n. lymph. Evaluated, median (Q1, Q3) & $23(19,30)$ & $23(18,29)$ & 0.4557 \\
\hline \% lymph. Metastatic, median (Q1, Q3) & $11.1(5.6,31.8)$ & $9.5(4.5,25)$ & 0.2062 \\
\hline LVI, n (\%) & $29(46.8)$ & $80(29.6)$ & 0.0095 \\
\hline
\end{tabular}

Abbreviations: BCRL breast cancer related lymphoedema, NST invasive breast cancer of no special type, ER estrogen receptor, HER2 human epidermal growth factor receptor 2, ENE extranodal extension, LVI lymphovascular invasion

${ }^{\text {a }}$ Tumor dimension (T) according to TNM classification was as follows: T1, Tumor $\leq 20 \mathrm{~mm}$ in greatest dimension; T2, Tumor $>20 \mathrm{~mm}$ but $\leq 50 \mathrm{~mm}$ in greatest dimension; T3, Tumor $>50 \mathrm{~mm}$ in greatest dimension; T4, Tumor of any size with direct extension to the chest wall and/or to the skin (ulceration or skin nodules) ${ }^{b}$ Pathologic lymph node status (pN) according to TNM classification was as follows: pN0, negative; pN1, 1 to 3 positive lymph nodes; pN2, metastases in 4-9 axillary lymph nodes; $\mathrm{pN} 3$, metastases in $\geq 10$ axillary lymph nodes

'Grading was established using the Nottingham histologic grading system

${ }^{\mathrm{d}}$ HER2 status was assessed using immunochemistry and chromogenic in-situ hybridization in borderline cases

ePositivity for Ki67 was defined as $\geq 10 \%$

right-handed individuals than the general population [45]. Following this assumption, up to $95 \%$ of the BCRL women were right-dominant. Therefore, our data provide circumstantial evidence to suggest that even the physiological use of the dominant arm has a protective role against BCRL and that women with metastatic breast cancer of the left breast are at higher risk for this condition. Furthermore, we corroborate the notion that even a minimal amount of physical activity has the potential to reduce the likelihood of arm swelling. 


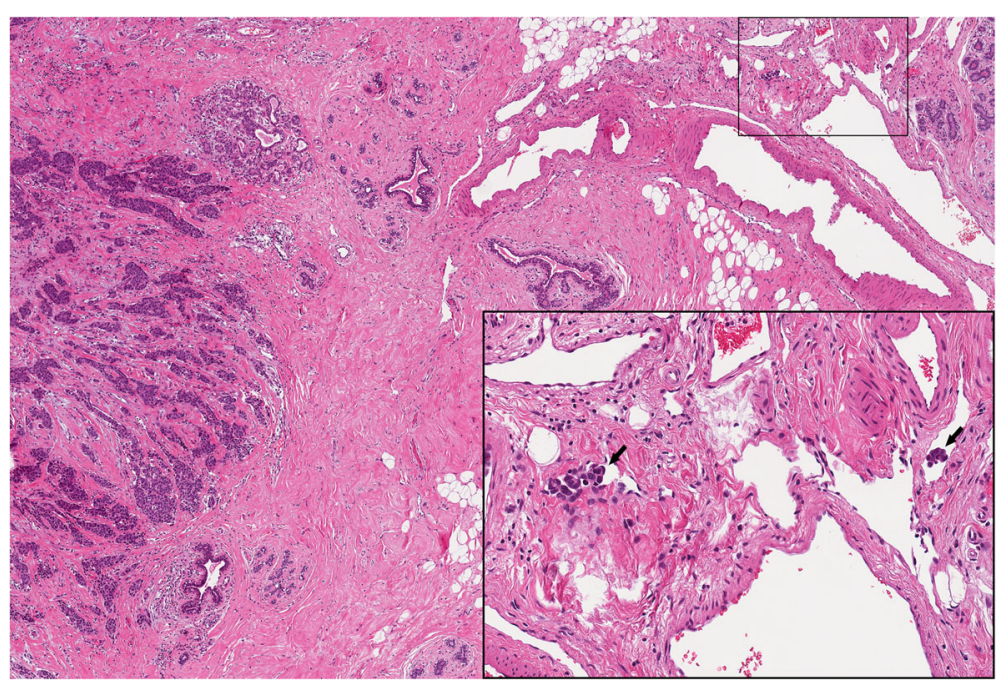

Fig. 2 Morphological features of lymphovascular invasion in a patient with breast cancer related lymphoedema after surgery. Representative micrographs of a moderately differentiated invasive carcinoma of no special type showing peritumoral cluster of neoplastic cells inside the lumen of small vessels, as highlighted by the arrows in the inset on the bottom right. One of the two metastatic clusters determined partial lumen obliteration. H\&E, original magnification $\times 100$, inset $\times 400$

Given that no previous study focused on tumour-specific clinicopathological features of the primary tumour to assess BCRL risk, we sought to analyse a pool of histology-based prognostic parameters. Taken together, we observed an overall high frequency of ENE-positive tumors (63\%), consistent with previous data on large-scale studies considering any penetration of the lymph node capsule as ENE [35-37]. Hence, this feature shows a high variability in the literature, ranging from 23 to $66 \%$ of metastatic breast carcinomas [34, 37, 46-52]. In contrast to LVI, there is currently lack of consensus on how to determine and report ENE, with some groups employing the cut-off value of $2 \mathrm{~mm}$ of perpendicular diameter for its assessment [34, 52, 53]. Interestingly, we observed that both LVI and ENE are associated with a poorer outcome in terms of BCRL-free survival when considered in the bivariate analyses. Surprisingly, when the laterality was incorporated in a multivariate model

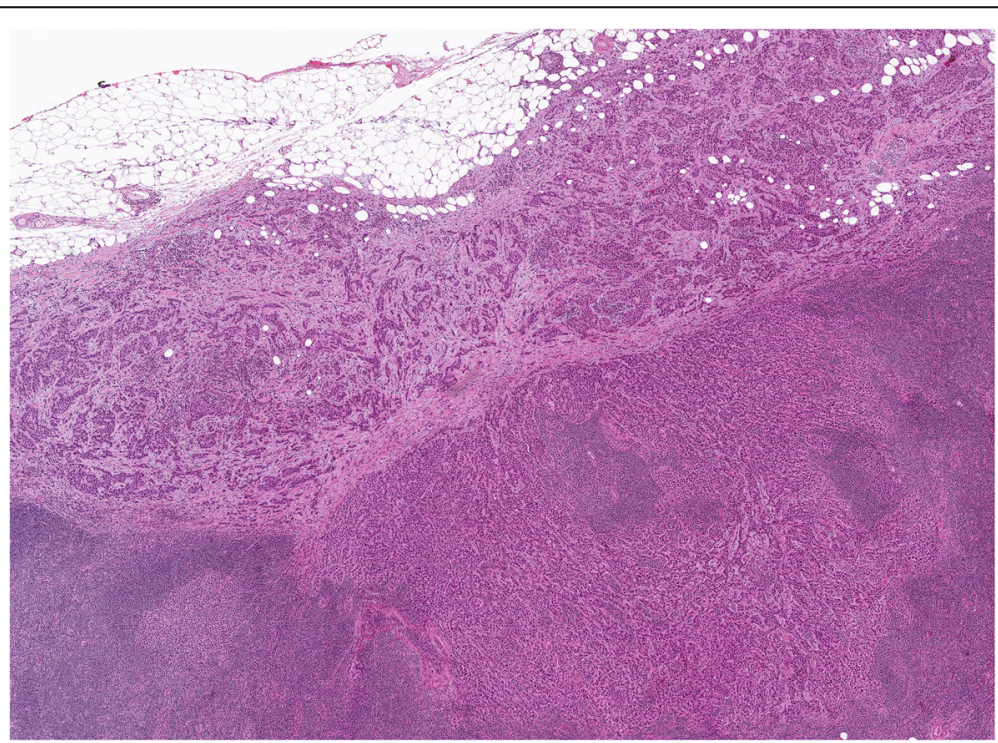

Fig. 3 Morphological features of extranodal extension of a lymph node metastasis in a patient with breast cancer related lymphoedema after surgery. Representative micrographs of the axillary lymph node macro-metastasis from a moderately differentiated invasive carcinoma of no special type with extranodal extension to the peri-lymph node adipose tissue. H\&E, original magnification $\times 100$ 


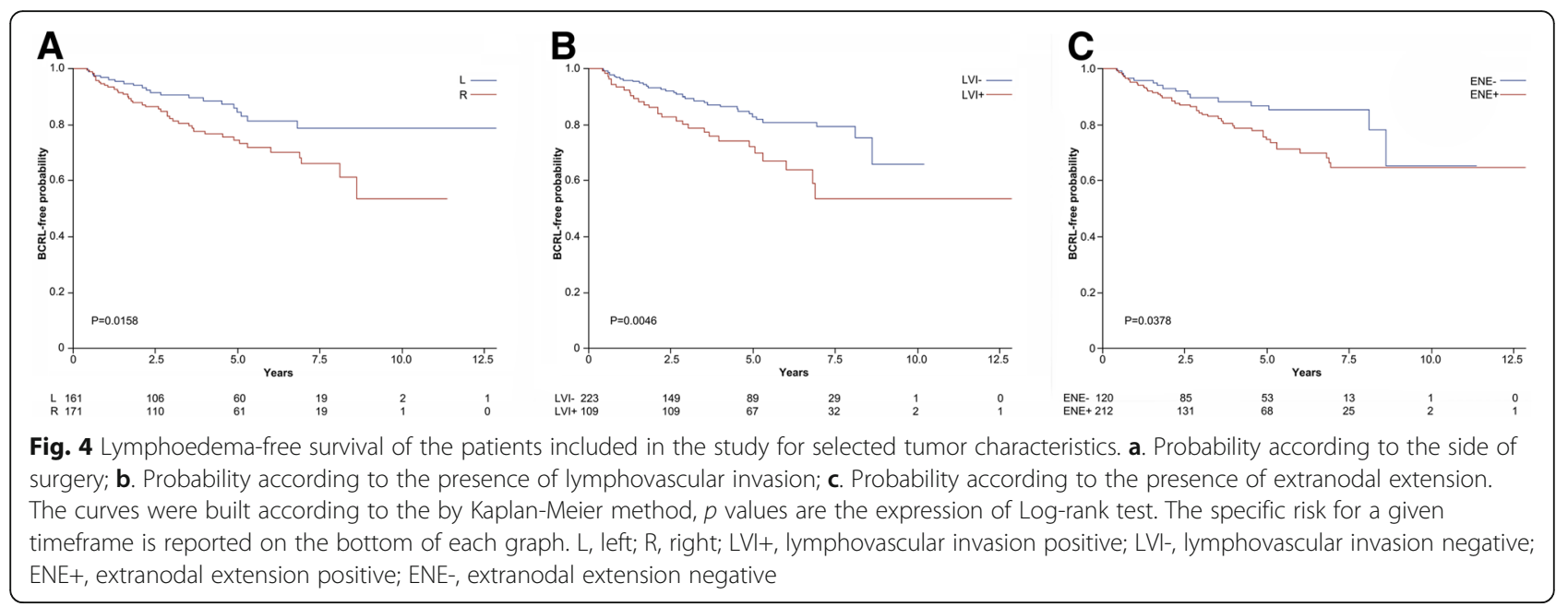

encompassing the hormone receptor status and subsequent hormone therapy, we observed that patients with left-sided breast cancer showing peritumoral LVI have four times higher risk to develop BCRL compared to patients with LVI-negative tumours of the left breast. On the other hand, patients with cancer of the right breast whose metastases showed ENE and that underwent surgery in the homolateral axilla harbour three times higher $\mathrm{HR}$ of BCRL in comparison to patients with ENE-negative tumours. No statistically significant interaction between LVI and ENE were observed, therefore no attempt to isolate two distinct populations of patients with either LVI or ENE was made. Notably, the hormone therapy was involved in BCRL occurrence, consistent with the role of ER as modulator of the vascular tropism [54].

Table 3 General characteristics of patients and pathological factors associated with the development of BCRL

\begin{tabular}{|c|c|c|c|c|}
\hline & & $\mathrm{HR}$ & $95 \% \mathrm{Cl}$ & $p$-value \\
\hline \multicolumn{2}{|c|}{ Infections } & 2.20 & $0.99-4.92$ & 0.0540 \\
\hline \multicolumn{2}{|c|}{ Dyslipidaemia } & 0.22 & $0.05-0.95$ & 0.0431 \\
\hline \multicolumn{2}{|c|}{ Body Mass Index $(\mathrm{BMI}) \geq 25 \mathrm{~kg} / \mathrm{m}^{2}$} & 1.09 & $0.65-1.84$ & 0.7368 \\
\hline \multicolumn{2}{|c|}{ Estrogen receptor positive } & 13.0 & $2.31-72.8$ & 0.0036 \\
\hline \multicolumn{2}{|c|}{ Progesterone receptor positive } & 0.44 & $0.15-1.28$ & 0.1326 \\
\hline \multicolumn{2}{|c|}{ Hormone therapy } & 0.02 & $0.01-0.09$ & $<0.0001$ \\
\hline \multicolumn{2}{|c|}{ Hormone therapy (time-dependent) } & 2.45 & $1.16-5.17$ & 0.0187 \\
\hline Side & \multicolumn{4}{|c|}{ Extranodal extension } \\
\hline Right & Yes vs. No & 3.38 & \multicolumn{2}{|l|}{$1.53-7.47$} \\
\hline Left & Yes vs. No & 0.74 & \multicolumn{2}{|l|}{$0.30-1.81$} \\
\hline Side & \multicolumn{4}{|c|}{ Lymphovascular invasion } \\
\hline Right & Yes vs. No & 1.41 & \multicolumn{2}{|l|}{$0.74-2.70$} \\
\hline Left & Yes vs. No & 3.80 & \multicolumn{2}{|l|}{$1.58-9.16$} \\
\hline
\end{tabular}

The hazard ratio (HR) of developing BCRL was calculated using Cox Proportional Hazard Model
The biology that underpins the role of these two prognostic factors based on the side of surgery could be hypothesized using physical algorithms. In particular, the propulsion of the lymphatic fluid in the collecting vessels is strongly affected by preload, afterload, and transmural pressure, as postulated by Frank-Starling law [55]. Shear stresses in addition to nerve and humoral mediators are also implicated in this complex mechanism [56]. Extrinsic stimuli such as skeletal muscle contraction during normal activities, the motion of adjacent organs and even arterial pulsations can also influence the lymphatic flow [56]. Passive flow owing to a positive pressure gradient may also occur in oedema, during which lymph formation and swelling are increased [57]. In murine models, Gashev et al. showed that the intrinsic drainage mechanism is dominant for low levels of lymph formation, but, as these levels arise, the active lymph pump is inhibited, and the vessels become conduits $[56,58]$. The different HR of developing BCRL found in a patient with $\mathrm{LVI} /$ side-left involved and ENE/side-right involved might be explained on the basis of the mechanisms regulating lymph node propulsion and drainage, since there are not significative anatomical differences between the lymphatic drainage of the two sides of the body [59]. Specifically, the smallest metastatic clusters of cells that are able to determine obstruction to the lymph drainage measure approximately $5-10 \mu \mathrm{m}$, which is the average capillary diameter [59]. Therefore, our results provide evidence, albeit circumstantial, to suggest that LVI can represent a physical obstacle to lymph drainage, particularly in small vessels [60]. This phenomenon can become more evident in the left arm, where the muscular pump that typically supports the normal drainage as a vis a tergo, is less represented in the non-dominant arm [61]. Furthermore, ENE of the metastatic clones can be physically referred to a breach in the lymph node capsule [56]. Interestingly, lymph nodes present a relatively high resistance to flow [62], while extrinsic mechanisms such as skeletal muscle 

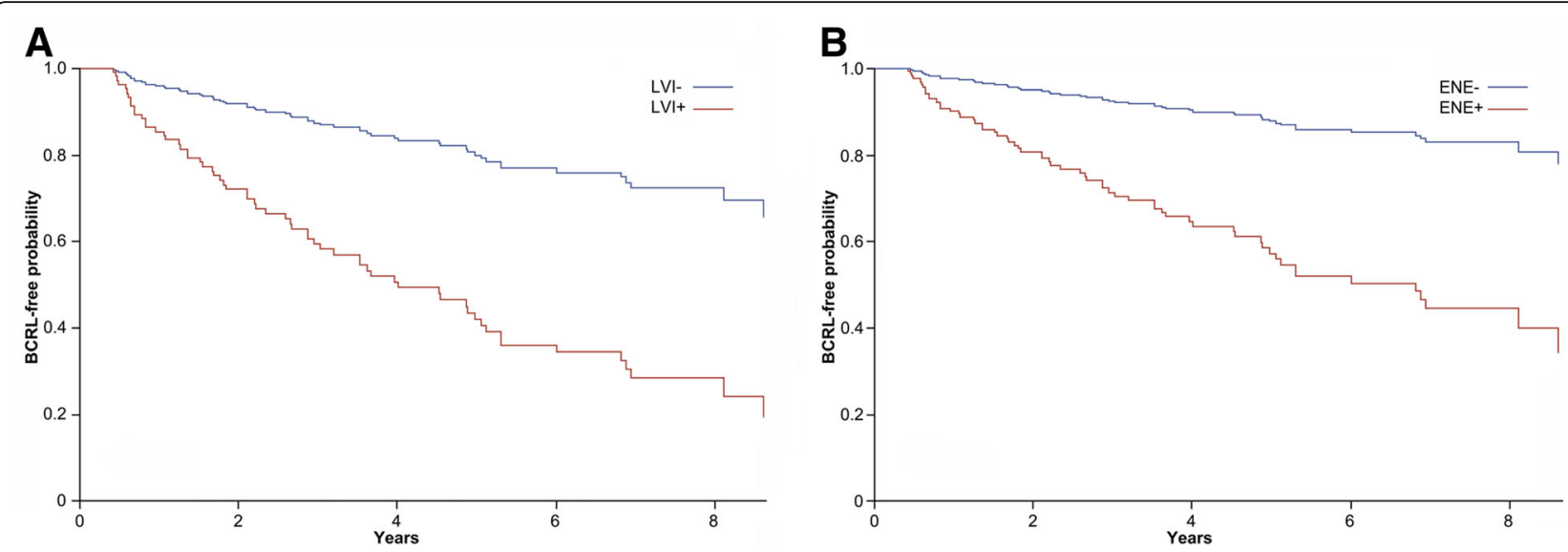

Fig. 5 Lymphoedema-free survival of the patients included in the study for selected tumor characteristics on the basis of the side of the surgery. a. Probability according to the presence of peritumoral lymphovascular invasion after surgery of the left axilla. $\mathbf{b}$. Probability according to the presence of extranodal extension of the lymph node metastasis after surgery of the right axilla. The curves are the result of a Cox proportional hazard regression analysis. LVI+, lymphovascular invasion positive; LVI-, lymphovascular invasion negative; ENE+, extranodal extension positive; ENE-, extranodal extension negative

contraction - a dominant factor if considering that around $90 \%$ of world population is right-handed [61] - could be responsible for the continuous compression of those breached lymph nodes. It should be noted, however, that this proposed mechanism has necessarily to take place before surgery and the consequent removal of axillary lymph glands. Still, a latent and subclinical form of lymphoedema could represent a possible scenario even in pre-surgical settings, thus ascribing to surgery an unmasking role by disrupting axillary anatomical structures. This hypothesis is supported by a recent prospective study performed on 1028 breast cancer women, showing that, without baseline (preoperative) evaluation of the arms symmetry, up to $50 \%$ of BCRL cases can be missed [63]. Further clinical studies coupled with functional experiments are warranted to explore the complexity of BCRL pathogenesis, also in lights of these novel observations.

This study has several limitations. First, given its retrospective nature, it was not possible to obtain a baseline measurement of the limb prior to surgery and prior to the development of macroscopic BCRL, while the comparison of the two arms might be suboptimal as upper limbs are rarely symmetrical at baseline [63]. Second, all the measurements were not taken at regular intervals but either during routine follow-up visits or after the patient personally contacted the oncologist. Third, mild and asymptomatic forms of BCRL may not always be recorded. These intrinsic limitations could have led to an underestimation of the BCRL incidence in our population of patients. However, this study should be considered hypothesis-generating, as it provides previously unavailable data on pathologic risk indicators of BCRL. Furthermore, there are several lines of evidence that regional nodal irradiation is associated with a significantly higher risk of lymphedema than no irradiation or irradiation of the breast/chest wall after axillary nodes dissection [2] Hence, recent data (e.g. The European Organisation for Research and Treatment of Cancer (EORTC) and the National Cancer Institute of Canada MA-20 trials) support an increasing role of regional nodal irradiation in the treatment of breast cancer, particularly in early-stage tumors with high-risk features, such as extranodal extension. However, none of our BCRL patients were subjected to axillary radiotherapy, given that they were all surgically-treated in a timeframe ranging from 1998 and 2015. For this reason, it was not possible perform correlations between axillary radiation and BCRL occurrence. On the other hand, we confirm that irradiation of the residual breast, supraclavicular fossa, and/ or chest wall should not be considered as risk factors for BCRL development. Further large-scale prospective studies, coupled with standardized BCRL scoring systems, are warranted to define the clinical impact of our findings. Despite these limitations, our work paves the way to a novel tailored clinical approach to BCRL, where an integrative screening platform taking into account clinicopathologic variables together with surgical information could be pragmatically employed on pre-surgical core biopsies and sentinel lymph node procedure. Furthermore, the present study provides novel insights for the set-up of future prospective studies to identify and understand the molecular basis of BCRL with the integration of intrinsic prognostic and predictive biomarkers.

\section{Conclusion}

This study represents the first analysis of BCRL to provide preliminary data of bona fide tumour-specific risk indicators, such as laterality of the surgery and the presence of LVI and ENE. Our observations suggest that the routinary evaluation of LVI and ENE either on pre-surgical (e.g. core 
biopsies), intra-surgical (e.g. intraoperative sentinel lymph nodes), or post-surgical (e.g. breast and axillary nodes excision) samples might represent the basis for a novel strategy in the identification of patients at higher risk of BCRL. This could have tremendous implications for BCRL management, leading to the development of innovative tailored treatment protocols, even at pre-surgery level.

\section{Additional file}

Additional file 1: Table S1. Selected clinicopathologic features of the patients included in this study according to the side of surgery. Table S2. Extranodal extension and lymphovascular invasion subgroups of breast cancers according to the side of surgery. Figure $\mathbf{S 1}$. Lymphedema-free survival of the patients included in the study for selected tumor characteristics on the basis of the side of the surgery. (PDF $433 \mathrm{~kb}$ )

\section{Abbreviations}

BCRL: Breast cancer related lymphoedema; BMI: Body mass index; Cl: Confidence interval; ENE: Extranodal extension; ER: Oestrogen receptor; HER2: Human epidermal growth factor receptor 2; HR: Hazard ratio; LVI: Lymphovascular invasion; PR: Progesterone receptor; SD: Standard deviation

\section{Funding}

M.I. is funded in part by the Edo and Elvo Tempia Foundation, Biella, Italy. G.L. is funded by an OXIAMO Onlus Post-Graduate Fellowship.

\section{Availability of data and materials}

The dataset used and analysed during the present study is available from the corresponding author upon reasonable request.

\section{Authors' contributions \\ Study concept, design, and supervision by NF and MI. Acquisition, analysis, and interpretation of data: CC, GL, AM, DL, EGR, DG, and MI. GL, AM, LD, and $D G$ reviewed the clinical records. Clinicopathologic correlations were performed by $\mathrm{CC}, \mathrm{MI}$, and $\mathrm{NF}$, with the substantial contribution of $\mathrm{AM}$ and EGR. Initial histologic review of the cases was performed by $G L$ and NF, while CC and GL interpreted the morphology and immunohistochemical results. The statistical analysis was carried out by SM and MN. Iconography and image processing by GL and NF. CC wrote the first draft of the manuscript, which was initially reviewed by MI and NF. Subsequently, all authors edited and approved the final draft.}

\section{Ethics approval and consent to participate}

The study was approved by the ethics committee of the Fondazione IRCCS $\mathrm{Ca}^{\prime}$ Granda under the vote \#179/13. All participants signed informed consent forms.

\section{Consent for publication}

Not applicable.

\section{Competing interests}

The authors declare that they have no competing interests.

\section{Publisher's Note}

Springer Nature remains neutral with regard to jurisdictional claims in published maps and institutional affiliations.

\footnotetext{
Author details

'Physical and Rehabilitative Medicine, Department of Health Sciences, University of Eastern Piedmont "A. Avogadro", Viale Piazza D'Armi 1, 28100 Novara, Italy. ${ }^{2}$ Division of Pathology, Fondazione IRCCS Ca' Granda, Ospedale Maggiore Policlinico, Via Francesco Sforza 35, 20122 Milan, Italy. ${ }^{3}$ School of Medicine, University of Milan, Via Festa del Perdono 7, 20122 Milan, Italy. ${ }^{4}$ Division of Breast Surgery, Fondazione IRCCS Ca' Granda, Ospedale Maggiore Policlinico, Via Francesco Sforza 35, 20122 Milan, Italy. ${ }^{5}$ Division of
}

Medical Oncology, Fondazione IRCCS Ca' Granda, Ospedale Maggiore Policlinico, Via Francesco Sforza 35, 20122 Milan, Italy. ${ }^{6}$ School of Pathology, University of Milan, Via Festa del Perdono 7, 20122 Milan, Italy. ${ }^{7}$ Department of Pathology, European Institute of Oncology, Via Giuseppe Ripamonti 435, 20141 Milan, Italy. ${ }^{8}$ Department of Oncology and Hemato-oncology, University of Milan, Via Commenda 10, 20122 Milan, Italy. ${ }^{9}$ National Research Council (CNR), Neuroscience Institute Aging Branch, Via Giustiniani 2, 35128 Padua, Italy. ${ }^{10}$ Department of Biomedical, Surgical and Dental Sciences, University of Milan, Via Commenda 10, 20122 Milan, Italy.

Received: 18 April 2018 Accepted: 24 September 2018 Published online: 29 September 2018

\section{References}

1. Asdourian MS, Skolny MN, Brunelle C, Seward CE, Salama L, Taghian AG Precautions for breast cancer-related lymphoedema: risk from air travel, ipsilateral arm blood pressure measurements, skin puncture, extreme temperatures, and cellulitis. Lancet Oncol. 2016;17:e392-405.

2. Shaitelman SF, Chiang YJ, Griffin KD, DeSnyder SM, Smith BD, Schaverien MV, Woodward WA, Cormier JN. Radiation therapy targets and the risk of breast cancer-related lymphedema: a systematic review and network metaanalysis. Breast Cancer Res Treat. 2017;162:201-15.

3. Coriddi M, Khansa I, Stephens J, Miller M, Boehmler J, Tiwari P. Analysis of factors contributing to severity of breast cancer-related lymphedema. Ann Plast Surg. 2015;74:22-5.

4. Specht MC, Miller CL, Russell TA, Horick N, Skolny MN, O'Toole JA, Jammallo LS, Niemierko A, Sadek BT, Shenouda MN, et al. Defining a threshold for intervention in breast cancer-related lymphedema: what level of arm volume increase predicts progression? Breast Cancer Res Treat. 2013;140:485-94.

5. Sayegh HE, Asdourian MS, Swaroop MN, Brunelle CL, Skolny MN, Salama L, Taghian AG. Diagnostic methods, risk factors, prevention, and Management of Breast Cancer-Related Lymphedema: past, present, and future directions. Curr Breast Cancer Rep. 2017;9:111-21.

6. DiSipio T, Rye S, Newman B, Hayes S. Incidence of unilateral arm lymphoedema after breast cancer: a systematic review and meta-analysis. Lancet Oncol. 2013;14:500-15.

7. Brunelle C, Skolny M, Ferguson C, Swaroop M, O'Toole J, Taghian AG. Establishing and sustaining a prospective screening program for breast cancer-related lymphedema at the Massachusetts general hospital: lessons learned. J Pers Med. 2015;5:153-64.

8. Erickson VS, Pearson ML, Ganz PA, Adams J, Kahn KL. Arm edema in breast cancer patients. J Natl Cancer Inst. 2001;93:96-111.

9. Ahmed RL, Prizment A, Lazovich D, Schmitz KH, Folsom AR. Lymphedema and quality of life in breast cancer survivors: the lowa Women's health study. J Clin Oncol. 2008;26:5689-96.

10. Cormier JN, Xing Y, Zaniletti I, Askew RL, Stewart BR, Armer JM. Minimal limb volume change has a significant impact on breast cancer survivors. Lymphology. 2009:42:161-75.

11. Boyages J, Kalfa S, Xu Y, Koelmeyer L, Mackie H, Viveros H, Taksa L, Gollan P. Worse and worse off: the impact of lymphedema on work and career after breast cancer. Springerplus. 2016;5:657.

12. Lymphoedema Framework. Best practice for the Management of Lymphoedema. International consensus. London: MEP Ltd; 2006.

13. Runowicz CD, Leach CR, Henry NL, Henry KS, Mackey HT, Cowens-Alvarado RL, Cannady RS, Pratt-Chapman ML, Edge SB, Jacobs LA, et al. American Cancer Society/American Society of Clinical Oncology breast Cancer survivorship care guideline. J Clin Oncol. 2016;34:611-35.

14. Cardoso F, Costa A, Senkus E, Aapro M, André F, Barrios CH, Bergh J, Bhattacharyya G, Biganzoli L, Cardoso MJ, et al. 3rd ESO-ESMO international consensus guidelines for advanced breast Cancer (ABC 3). Ann Oncol. 2017;28:16-33.

15. Canavese G, Bruzzi P, Catturich A, Tomei D, Carli F, Garrone E, Spinaci S, Lacopo F, Tinterri C, Dozin B. Sentinel lymph node biopsy versus axillary dissection in node-negative early-stage breast Cancer: 15-year follow-up update of a randomized clinical trial. Ann Surg Oncol. 2016;23:2494-500.

16. Donker M, van Tienhoven G, Straver ME, Meijnen P, van de Velde CJ, Mansel RE, Cataliotti L, Westenberg AH, Klinkenbij JH, Orzalesi L, et al. Radiotherapy or surgery of the axilla after a positive sentinel node in breast cancer (EORTC 10981-22023 AMAROS): a randomised, multicentre, open-label, phase 3 non-inferiority trial. Lancet Oncol. 2014;15:1303-10.

17. Lucci A, McCall LM, Beitsch PD, Whitworth PW, Reintgen DS, Blumencranz PW, Leitch AM, Saha S, Hunt KK, Giuliano AE, Group ACoSO. Surgical complications 
associated with sentinel lymph node dissection (SLND) plus axillary lymph node dissection compared with SLND alone in the American College of Surgeons oncology group trial Z0011. J Clin Oncol. 2007;25:3657-63.

18. Huang TW, Tseng SH, Lin CC, Bai CH, Chen CS, Hung CS, Wu CH, Tam KW. Effects of manual lymphatic drainage on breast cancer-related lymphedema: a systematic review and meta-analysis of randomized controlled trials. World J Surg Oncol. 2013;11:15.

19. Seyednejad N, Kuusk U, Wiseman SM. Axillary reverse lymphatic mapping in breast cancer surgery: a comprehensive review. Expert Rev Anticancer Ther. 2014;14:771-81.

20. Boccardo FM, Casabona F, Friedman D, Puglisi M, De Cian F, Ansaldi F, Campisi C. Surgical prevention of arm lymphedema after breast cancer treatment. Ann Surg Oncol. 2011;18:2500-5.

21. Dayes IS, Whelan TJ, Julian JA, Parpia S, Pritchard KI, D'Souza DP, Kligman L, Reise D, LeBlanc L, McNeely ML, et al. Randomized trial of decongestive lymphatic therapy for the treatment of lymphedema in women with breast cancer. J Clin Oncol. 2013;31:3758-63.

22. Stuiver MM, ten Tusscher MR, Agasi-Idenburg CS, Lucas C, Aaronson NK, Bossuyt PM. Conservative interventions for preventing clinically detectable upper-limb lymphoedema in patients who are at risk of developing lymphoedema after breast cancer therapy. Cochrane Database Syst Rev. 2015;2:CD009765.

23. Ferlay J, Soerjomataram I, Dikshit R, Eser S, Mathers C, Rebelo M, Parkin DM, Forman D, Bray F. Cancer incidence and mortality worldwide: sources, methods and major patterns in GLOBOCAN 2012. Int J Cancer. 2015;136:E359-86.

24. Tewari N, Gill PG, Bochner MA, Kollias J. Comparison of volume displacement versus circumferential arm measurements for lymphoedema: implications for the SNAC trial. ANZ J Surg. 2008;78:889-93.

25. Taylor R, Jayasinghe UW, Koelmeyer L, Ung O, Boyages J. Reliability and validity of arm volume measurements for assessment of lymphedema. Phys Ther. 2006;86:205-14.

26. Hidding JT, Viehoff PB, Beurskens $\mathrm{CH}$, van Laarhoven HW, Nijhuis-van der Sanden MW, van der Wees PJ. Measurement properties of instruments for measuring of lymphedema: systematic review. Phys Ther. 2016;96:1965-81

27. Lakhani SR, Ellis IO, Schnitt SJ, Tan PH, van de Vijver MJ. WHO classification of Tumours of the breast. Fourth Edition. Lyon: IARC Press; 2012

28. Elston CW, Ellis IO. Pathological prognostic factors in breast cancer. I. the value of histological grade in breast cancer: experience from a large study with long-term follow-up. Histopathology. 1991;19:403-10.

29. Amin MB, Greene FL, Edge SB, Compton CC, Gershenwald JE, Brookland RK, Meyer L, Gress DM, Byrd DR, Winchester DP. The eighth edition AJCC Cancer staging manual: continuing to build a bridge from a populationbased to a more "personalized" approach to cancer staging. CA Cancer J Clin. 2017:67:93-9.

30. Ercoli G, Lopez G, Ciapponi C, Corti C, Despini L, Gambini D, Runza L, Blundo C, Sciarra A, Fusco N. Building up a high-throughput screening platform to assess the heterogeneity of HER2 gene amplification in breast cancers. J Vis Exp. 2017.

31. Curigliano G, Burstein HJ, P Winer E, Gnant M, Dubsky P, Loibl S, Colleoni M Regan MM, Piccart-Gebhart M, Senn HJ, et al. De-escalating and escalating treatments for early-stage breast cancer: the St. Gallen international expert consensus conference on the primary therapy of early breast Cancer 2017 Ann Oncol. 2017;28:1700-12

32. Rosen PP. Tumor emboli in intramammary lymphatics in breast carcinoma: pathologic criteria for diagnosis and clinical significance. Pathol Annu. 1983;18(Pt 2):215-32.

33. Lee AH, Pinder SE, Macmillan RD, Mitchell M, Ellis IO, Elston CW, Blamey RW Prognostic value of lymphovascular invasion in women with lymph node negative invasive breast carcinoma. Eur J Cancer. 2006;42:357-62.

34. Gooch J, King TA, Eaton A, Dengel L, Stempel M, Corben AD, Morrow M. The extent of extracapsular extension may influence the need for axillary lymph node dissection in patients with T1-T2 breast cancer. Ann Surg Oncol. 2014;21:2897-903.

35. Gruber G, Cole BF, Castiglione-Gertsch M, Holmberg SB, Lindtner J, Golouh R, Collins J, Crivellari D, Thürlimann B, Simoncini E, et al. Extracapsular tumor spread and the risk of local, axillary and supraclavicular recurrence in node-positive, premenopausal patients with breast cancer. Ann Oncol. 2008;19:1393-401.

36. Gruber G, Bonetti M, Nasi ML, Price KN, Castiglione-Gertsch M, Rudenstam CM, Holmberg SB, Lindtner J, Golouh R, Collins J, et al. Prognostic value of extracapsular tumor spread for locoregional control in premenopausal patients with node-positive breast cancer treated with classical cyclophosphamide, methotrexate, and fluorouracil: long-term observations from international breast Cancer study group trial VI. J Clin Oncol. 2005;23:7089-97.

37. Dobi E, Bazan F, Dufresne A, Demarchi M, Villanueva C, Chaigneau L, Montcuquet $P$, Ivanaj A, Sautière $J L$, Maisonnette-Escot $Y$, et al. Is extracapsular tumour spread a prognostic factor in patients with early breast cancer? Int J Clin Oncol. 2013;18:607-13.

38. Hosmer DW, Lemeshow S, May S. Applied survival analysis: regression modeling of time-to-event data. New York: Wiley; 2011.

39. Vittinghoff $E$, McCulloch CE. Relaxing the rule of ten events per variable in logistic and cox regression. Am J Epidemiol. 2007;165:710-8.

40. Denis DJ. Applied univariate, bivariate, and multivariate statistics. Hoboken: Wiley; 2015.

41. Fusco N, Guerini-Rocco E, Del Gobbo A, Franco R, Zito-Marino F, Vaira V, Bulfamante G, Ercoli G, Nosotti M, Palleschi A, et al. The contrasting role of p16Ink4A patterns of expression in neuroendocrine and non-neuroendocrine lung tumors: a comprehensive analysis with Clinicopathologic and molecular correlations. PLoS One. 2015;10:e0144923.

42. Rakha EA, El-Sayed ME, Lee AH, Elston CW, Grainge MJ, Hodi Z, Blamey RW, Ellis 10 . Prognostic significance of Nottingham histologic grade in invasive breast carcinoma. J Clin Oncol. 2008:26:3153-8.

43. Rogan S, Taeymans J, Luginbuehl H, Aebi M, Mahnig S, Gebruers N. Therapy modalities to reduce lymphoedema in female breast cancer patients: a systematic review and meta-analysis. Breast Cancer Res Treat. 2016;159:1-14.

44. Schmitz KH, Ahmed RL, Troxel AB, Cheville A, Lewis-Grant L, Smith R, Bryan CJ, Williams-Smith CT, Chittams J. Weight lifting for women at risk for breast cancer-related Iymphedema: a randomized trial. JAMA. 2010;304:2699-705.

45. Papadatou-Pastou M, Tomprou DM. Intelligence and handedness: metaanalyses of studies on intellectually disabled, typically developing, and gifted individuals. Neurosci Biobehav Rev. 2015;56:151-65.

46. Nottegar A, Veronese N, Senthil M, Roumen RM, Stubbs B, Choi AH, Verheuvel NC, Solmi M, Pea A, Capelli P, et al. Extra-nodal extension of sentinel lymph node metastasis is a marker of poor prognosis in breast cancer patients: a systematic review and an exploratory meta-analysis. Eur J Surg Oncol. 2016;42:919-25.

47. Aziz S, Wik E, Knutsvik G, Klingen TA, Chen Y, Davidsen B, Aas H, Aas T, Akslen LA. Extra-nodal extension is a significant prognostic factor in lymph node positive breast cancer. PLoS One. 2017;12:e0171853.

48. Stranzl $H$, Ofner $P$, Peintinger $F$. Postoperative irradiation in breast cancer patients with one to three positive axillary lymph nodes. Is there an impact of axillary extranodal tumor extension on locoregional and distant control? Strahlenther Onkol. 2006;182:583-8.

49. Bucci JA, Kennedy CW, Burn J, Gillett DJ, Carmalt HL, Donnellan MJ, Joseph MG, Pendlebury SC. Implications of extranodal spread in node positive breast cancer: a review of survival and local recurrence. Breast. 2001;10:213-9.

50. Drinka E, Allen P, McBride A, Buchholz T, Sahin A. Metastatic tumor volume and Extranodal tumor extension: clinical significance in patients with stage II breast Cancer. Arch Pathol Lab Med. 2015;139:1288-94.

51. Neri A, Marrelli D, Roviello F, De Stefano A, Guarnieri A, Pallucca E, Pinto E. Prognostic value of extracapsular extension of axillary lymph node metastases in T1 to T3 breast cancer. Ann Surg Oncol. 2005;12:246-53.

52. Choi AH, Surrusco M, Rodriguez S, Bahjri K, Solomon N, Garberoglio C, Lum S, Senthil M. Extranodal extension on sentinel lymph node dissection: why should we treat it differently? Am Surg. 2014;80:932-5.

53. Katz A, Strom EA, Buchholz TA, Thames HD, Smith CD, Jhingran A, Hortobagyi G, Buzdar AU, Theriault R, Singletary SE, McNeese MD. Locoregional recurrence patterns after mastectomy and doxorubicinbased chemotherapy: implications for postoperative irradiation. J Clin Oncol. 2000;18:2817-27.

54. Helmestam M, Andersson H, Stavreus-Evers A, Brittebo E, Olovsson M. Tamoxifen modulates cell migration and expression of angiogenesis-related genes in human endometrial endothelial cells. Am J Pathol. 2012;180:2527-35.

55. Widmaier PE, Hershel R, Strang KT. Vander's Human Physiology: The Mechanisms of Body Function. 14th ed. edn. New York: McGraw-Hill Education; 2016.

56. Margaris KN, Black RA. Modelling the lymphatic system: challenges and opportunities. J R Soc Interface. 2012;9:601-12.

57. Aukland K. Arnold Heller and the lymph pump. Acta Physiol Scand. 2005; 185:171-80.

58. Gashev AA, Delp MD, Zawieja DC. Inhibition of active lymph pump by simulated microgravity in rats. Am J Physiol Heart Circ Physiol. 2006;290:H2295-308. 
59. Standring S: Gray's Anatomy, The Anatomical Basis of Clinical Practice. 41st ed. edn: Elsevier; 2015.

60. Zhang D, Zhao L, Zhou P, Ma H, Huang F, Jin M, Dai X, Zheng X, Huang S, Zhang T. Circulating tumor microemboli (CTM) and vimentin+ circulating tumor cells (CTCS) detected by a size-based platform predict worse prognosis in advanced colorectal cancer patients during chemotherapy. Cancer Cell Int. 2017;17:6.

61. Hardyck C, Petrinovich LF. Left-handedness. Psychol Bull. 1977;84:385-404.

62. Papp M, Makara GB, Hajtman B. The resistance of in situ perfused lymph trunks and lymph nodes to flow. Experientia. 1971;27:391-2.

63. Sun F, Skolny MN, Swaroop MN, Rawal B, Catalano PJ, Brunelle CL, Miller CL, Taghian AG. The need for preoperative baseline arm measurement to accurately quantify breast cancer-related lymphedema. Breast Cancer Res Treat. 2016;157:229-40.

- fast, convenient online submission

- thorough peer review by experienced researchers in your field

- rapid publication on acceptance

- support for research data, including large and complex data types

- gold Open Access which fosters wider collaboration and increased citations

- maximum visibility for your research: over $100 \mathrm{M}$ website views per year

At BMC, research is always in progress.

Learn more biomedcentral.com/submissions 